\title{
Plasma deoxyuridine as a surrogate marker for toxicity and early clinical response in patients with metastatic colorectal cancer after 5-FU-based therapy in combination with arfolitixorin
}

\author{
Helena Taflin ${ }^{1}$ - Elisabeth Odin ${ }^{1} \cdot$ Göran Carlsson ${ }^{1} \cdot$ Roger Tell $^{2} \cdot$ Bengt Gustavsson ${ }^{1} \cdot$ Yvonne Wettergren ${ }^{1}(0)$
}

Received: 14 July 2020 / Accepted: 6 October 2020 / Published online: 24 October 2020

(C) The Author(s) 2020

\begin{abstract}
Purpose The aim was to explore the correlation between increasing doses of [6R]-5,10-methylenetetrahydrofolate (arfolitixorin) and plasma concentrations of deoxyuridine (dUr) in patients with metastatic colorectal cancer (mCRC), subjected to 5-fluorouracil (5-FU)-based chemotherapy. The aim was further to investigate the possibility to predict toxicity and clinical response during treatment using gender, age, and plasma dUr as explanatory variables.

Methods Thirty-three patients from the ISO-CC-005 phase I/IIa study, which investigated safety and tolerability of arfolitixorin at four dose levels, were included. Toxicity and clinical response were evaluated after 4 cycles of chemotherapy. Plasma dUr was quantified before $(0 \mathrm{~h})$ and $24 \mathrm{~h}$ after 5-FU administration at the first (C1) and fourth (C4) cycle using LC-MS/MS. Fit modelling was used to predict toxicity and clinical response.

Results The dUr levels increased with increasing arfolitixorin dose. Females had higher total and haematological toxicity scores $(p=0.0004$ and 0.0089 , respectively), and needed dose reduction more often than males $(p=0.012)$. Fit modeling showed that gender and the dUr levels at C1-0 h and C4-24 h predicted total toxicity $(p=0.0011)$, whereas dUr C4-0 h alone was associated with gastrointestinal toxicity $(p=0.026)$. Haematological toxicity was predicted by gender and age $(p=0.0071)$. The haematological toxicity score in combination with the dUr levels at C1-24 $\mathrm{h}$ and C4-24 h predicted early clinical response $(p=0.018)$.

Conclusion The dUr level before and during administration of 5-FU and arfolitixorin was predictive for toxicity and early clinical response and could be a potential surrogate marker for thymidylate synthase inhibition in patients with mCRC.

Trial registration NCT02244632, first posted on ClinicalTrials.gov on September 19, 2014
\end{abstract}

Keywords Metastatic $\cdot 5$-Fluorouracil $\cdot$ Folate $\cdot$ Gender $\cdot$ Gastrointestinal toxicity $\cdot$ Haematological toxicity

\section{Introduction}

Colorectal cancer (CRC) is ranked as the third most common cancer worldwide, and in 2018, approximately 1.8 million people were diagnosed with the disease [1]. The base

Electronic supplementary material The online version of this article (https://doi.org/10.1007/s00280-020-04173-2) contains supplementary material, which is available to authorized users.

Yvonne Wettergren

yvonne.wettergren@gu.se

1 Department of Surgery, The Institute of Clinical Sciences, The Sahlgrenska Academy At University of Gothenburg, Göteborg, Sweden

2 Isofol Medical AB, Göteborg, Sweden treatment with curable intent for CRC is radical surgery, and for selected rectal tumors, surgery in combination with radiotherapy [2]. Chemotherapy is used in all settings, both neoadjuvant, with the intent of reducing the tumor burden and making the tumor resectable/less advanced; in the adjuvant setting after radical surgery to reduce the risk of recurrence; and in a pure palliative setting with the purpose of prolonging life $[3,4]$. Although novel combination treatments have been developed during the last years, 5 -fluorouracil (5-FU) plus the folate leucovorin ([6R,S]-5-formyltetrahydrofolate) is still a cornerstone in treatment of CRC [5].

$5-\mathrm{FU}$ is an analogue of uracil in which the hydrogen at position 5 is replaced by fluorine. Using the same mechanism to enter the cell as uracil, 5-FU is converted into the active metabolite fluorodeoxyuridine monophosphate (FdUMP), which forms an inhibitory ternary complex with 
one of the key enzymes in DNA synthesis, thymidylate synthase (TS), and [6R]-5,10-methylenetetrahydrofolate ([6R]MTHF). This results in the inhibition of thymidylate synthesis and impairment of both DNA synthesis and DNA repair (Fig. 1). TS inhibition causes a rise in the intracellular pool of the natural TS substrate deoxyuridine monophosphate (dUMP), leading to increased levels of deoxyuridine (dUr) in tissues and blood [6]. The greatest impact of treatment with 5-FU is on rapidly dividing cells, such as epithelial cells and most importantly, tumor cells [7].

The response rate of colorectal tumors to 5-FU monotherapy is only around $10 \%$. By adding leucovorin (the stable calcium salt of [6R,S]-5-formyltetrahydrofolic acid, i.e., calcium folinate), which is converted to [6R]-MTHF in the liver, the tumor response rate can be improved to $21 \%$ [8]. All marketed folates used in established regimes, require intracellular enzymatic conversion to the active metabolite [6R]-MTHF to have a clinical effect.

Previous studies have shown that there is a large interindividual difference in concentration of leucovorin in colorectal tumor tissue in response to a standardized dose of leucovorin [9]. This difference might be related to different expression levels of genes encoding influx and efflux folate transporters and of those involved in conversion of leucovorin to the active metabolite [6R]-MTHF [10-12]. Genderand age-associated pharmacokinetic differences have also been reported for folates and most oncologic drugs [13-15].

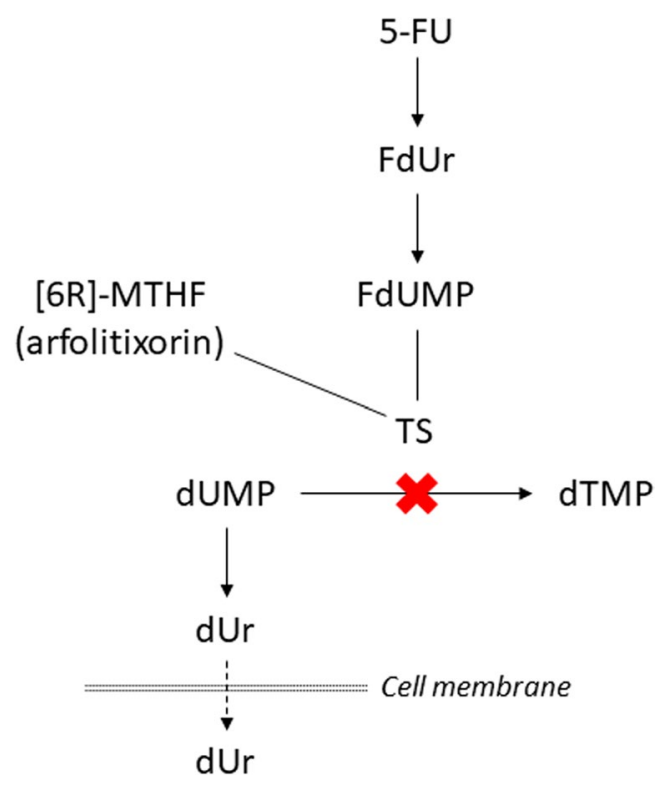

Fig. 1 Thymidylate synthase (TS) inhibitory effect on the pathway of thymidine nucleotides. Ternary complex formation with 5-fluorodeoxyuridine monophosphate (FdUMP) blocks the binding of deoxyuridine monophosphate (dUMP) to TS. Dephosphorylation of dUMP to deoxyuridine (dUr) leads to subsequent efflux of dUr into the blood circulation. 5-FU, 5-fluorouracil; dTMP, deoxythymidine monophosphate; FdUr, 5-fluorodeoxyuridine; THF, tetrahydrofolate
Female gender and older age are especially associated with severe toxicity during 5-FU-based chemotherapy and may affect clinical response $[16,17]$.

Arfolitixorin is the hemisulfate salt of [6R]-MTHF which is a stable formulation of the naturally occurring diastereoisomer of [6R]-MTHF [18]. Unlike commonly used folates, [6R]-MTHF does not need to undergo further metabolism and may participate directly in the formation of the FdUMPTS-MTHF ternary complex. Hence, arfolitixorin is expected to be efficacious in a larger proportion of patients with less inter- and intra-individual variability [19]. Arfolitixorin was previously compared to levo-leucovorin in a blinded, randomized trial including 32 patients scheduled for surgical resection due to colon cancer [18]. The folates were given as a peroperative single intravenous bolus dose of either $60 \mathrm{mg} / \mathrm{m}^{2}$ or $200 \mathrm{mg} / \mathrm{m}^{2}$. Tumor and mucosa tissue were obtained at surgery after administration of the folates. The results showed that the [6R]-MTHF and THF concentrations were significantly higher after administration of arfolitixorin compared to levo-leucovorin in both tumors and mucosa. These results indicate that there is a higher probability of reaching an optimal level of [6R]-MTHF after arfolitixorin administration.

The aim of the present study was to explore the correlation between increasing doses of arfolitixorin and plasma concentrations of $\mathrm{dUr}$ in patients with metastatic CRC (mCRC), subjected to arfolitixorin in combination with chemotherapy. The aim was further to investigate the possibility to predict the risk of toxicity and early clinical response during treatment using gender, age and the plasma dUr level as explanatory variables.

\section{Materials and methods}

\section{Study design}

The patients were all recruited from the ISO-CC-005 (NCT02244632) study, an open-label, multi-center, Phase I/IIa dose cohort trial of patients with mCRC treated with arfolitixorin in combination with a fixed dose of 5-FU, alone, or in combination with a fixed dose of oxaliplatin or irinotecan, and an optional addition of bevacizumab after eight weeks of treatment (Online Resource 1). The main inclusion criteria were mCRC, confirmed by biopsy from either primary tumor or metastatic sites, eligibility for 5-FU-based chemotherapy given as palliative treatment, age $\geq 18$ years, World Health Organization (WHO) performance status of $0-2$, and a life expectancy exceeding three months. The primary objective of the study was to characterise the safety and tolerability of escalating doses of arfolitixorin in combination with standardized chemotherapy regimens in different treatment lines in terms of toxicity during eight weeks of 
treatment. Although ISO-CC-005 was an international multicentre study with several recruiting sites in Europe, only one centre (Sahlgrenska University Hospital/Östra, Gothenburg Sweden) was selected to perform pharmacokinetic/ pharmacodynamic research.

\section{Patients}

Thirty-six patients were initially recruited for the pharmacokinetic/pharmacodynamic studies. Out of these, two were excluded due to withdrawal of informed consent, and one due to refusal of further treatment resulting in a cohort of 33 patients who received first-line $(n=23)$, second- $(n=8)$, or third-line $(n=2)$ treatment. Nineteen of the patients were male, whereas 14 were female. The median age was 66 years range 38-85). The primary tumors were located in the colon in 25 patients, and in the rectum in 8 patients. Demographic and clinicopathological characteristics of the patients are presented in Online Resource 2.

\section{Treatment and response evaluation}

The palliative treatment consisted of 5-FU and arfolitixorin as single treatment or in combination with irinotecan or oxaliplatin \pm bevacizumab for eight weeks (Online Resource $3)$. Four different doses of arfolitixorin were used: 30, 60, 120 and $240 \mathrm{mg} / \mathrm{m}^{2}$ administered two days in a row every two weeks. Treatment efficacy was evaluated by CT scans of the thorax/abdomen according to RECIST1.1 criteria. Clinical response was evaluated as complete response (CR), partial response (PR), stable disease (SD), or progressive disease (PD) after four cycles of chemotherapy.

\section{Toxicity evaluation}

Patients were assessed for toxicity grade after each treatment cycle during the four cycles of chemotherapy, using the National Cancer Institute's Common Terminology Criteria for Adverse Events (NCI-CTCAE) version 4.0. Toxicities known to be commonly related with given treatment (diarrhea, nausea, vomiting, stomatitis, leucopenia, neutropenia, thrombocytopenia, ocular toxicity, paresthesia, fatigue, and neuropathy) $[20,21]$ were selected for analysis and the highest toxicity grade during the four treatment cycles was noted. The total toxicity score of a patient was calculated by adding up the toxicity grades $(0-4)$ of each evaluated side effect. Thus, the minimal score would be zero, and the maximal score would be 44 . A gastrointestinal toxicity score including diarrhea, nausea, vomiting, and stomatitis was also calculated, as well as a haematological score including leucopenia, neutropenia, and thrombocytopenia. Furthermore, the need of dose reduction during treatment was recorded as yes or no.

\section{Sample collection}

To assess the level of overall TS inhibition, reflected as the change in dUr levels over time, blood samples were collected in pre-chilled heparinized tubes immediately before $(0 \mathrm{~h}), 24 \mathrm{~h}(24 \mathrm{~h})$, and $48 \mathrm{~h}(48 \mathrm{~h})$ after administration of the combination treatment on Days 1 and 2 of Cycle 1 (C1) and Cycle 4 (C4). Plasma was immediately isolated from the blood by centrifugation at $1520 \mathrm{~g}\left(4^{\circ} \mathrm{C}, 10 \mathrm{~min}\right)$. The plasma was kept frozen at $-80{ }^{\circ} \mathrm{C}$ until analysis.

\section{dUr analysis}

A method employing liquid chromatography mass spectrometry (LC-MS/MS) was developed for quantification of plasma dUr using chlorodeoxyuridine (CldUr) as internal standard (IS). It involved precipitation of protein by mixing $60 \mu \mathrm{l}$ of $1 \mathrm{M}$ trichloroacetic acid (TCA) with $300 \mu \mathrm{l}$ of plasma. After cooling the mixture on ice for $10 \mathrm{~min}, 15 \mu \mathrm{l}$ of $0.5 \mathrm{mM}$ CldUr was added. The mixture was vortexed and centrifuged at $21500 \mathrm{xg}$ for $10 \mathrm{~min}$ at $8^{\circ} \mathrm{C}$. The sample was then transferred to a $10 \mathrm{kDa}$ molecular weight cut-off membrane filter (Millipore) and centrifuged at $21500 \times g$ for $20 \mathrm{~min}$. The solution at the bottom of the centrifugation tube was analyzed on LC-MS/MS. Chromatographic separations were performed on a dC18 Atlantis column. The mobile phases were (A) $5 \mathrm{mM}$ acetic acid (HAc) and (B) $5 \mathrm{mM}$ HAc dissolved in $90 \%$ acetonitrile. The gradient profile over time is shown in Online Resource 4 and 5. The analytes were ionized in an electrospray interface (ESI) under negative-ion mode (Online Resource 6).

Linearity was assessed by constructing matrixmatched calibration curves $(n=10)$ of dUr. Calibration curves were linear over $2-275$ pmol dUr. The mean equations from 10 calibration curves were found to be $y=0.002435 \times-0.00020$. The least square regression calibration curve was $R^{2}=0.9987$ for dUr in plasma. Sensitivity was assessed by evaluating the limit of detection (LOD) and limit of quantification (LOQ) for the method. The LOD and LOQ values were defined as the lowest analyte concentration that could be detected. The LOD for dUr was $0.017 \mu \mathrm{M}$ and the LOQ was found to be $0.052 \mu \mathrm{M}$. Intraday precision was determined by running replicates $(n=5)$ at three levels (low, medium and high) of known dUr concentrations spiked in plasma on the same day. Inter-assay variability was determined by analyzing low, medium and high dUr concentration samples on 10 separate days. The precision was calculated from the relative standard deviation (RSD \%) and ranged from 2.9 to $8.5 \%$ whereas the variability over 10 days ranged from 7.6 to $9.8 \%$. 


\section{Statistics}

The JMP 13.0/SAS software (SAS Institute Inc. Cary, NC, USA) was used for the statistical analyses. Data were presented as means and standard deviations (SD) or as median values with ranges. Differences between groups were calculated using the Kruskal-Wallis test or the Pearson's Chi-square test. To compare sets of continuous parameters measured in the same sample (matched pairs), the Pearson correlation coefficient $(r)$ was calculated. Fit modelling by effect likelihood ratio tests was used to predict the effect of explanatory variables on toxicity and clinical response during chemotherapy. No correction for multiple testing was done. Values of $p<0.05$ were considered significant.

\section{Results}

\section{Toxicity scores versus gender and age}

The mean total, gastrointestinal, and haematological toxicity scores were $5.6 \pm 2.9,2.2 \pm 2.0$, and $1.7 \pm 1.8$, respectively. Female patients had higher toxicity scores compared with male patients (Fig. 2). The results also showed that more females than males needed to reduce the dose of chemotherapy during treatment $(p=0.013)$. There was a negative correlation between the gastrointestinal toxicity score and age $(r=-0.35, p=0.044)$, however, no significant correlation was seen between total toxicity score or haematological toxicity score and age.

\section{Clinical response by gender and age}

Fifty percent of the female patients had PR, compared to $26.3 \%$ of the males. In contrast, more males had SD (52.6\%) compared to females (28.6\%). However, the number of males and females with PD was equal $(21.1 \%$ and $21.4 \%$, respectively). The mean age was significantly lower in patients with PD $(55.1 \pm 11.3$ years $)$, compared to patients with $\mathrm{SD} /$ PR $(66.1 \pm 8.4$ years, $p=0.021)$.

\section{Clinical response by toxicity scores}

Patients who responded well to treatment (PR) had a higher mean haematological toxicity score compared to patients with stable or progressive disease (Online Resource 7). However, a significant association was not noted between clinical response and the total toxicity score or the gastrointestinal toxicity score.

\section{Plasma dUr analysis}

The mean $\pm \mathrm{SD}$ concentrations of $\mathrm{dUr}$ are presented in Online Resource 8. As shown, there was a large inter-individual variation in dUr plasma levels. There was an increase in dUr levels at C4-0 $\mathrm{h}$ and C4-24 h, compared to $\mathrm{C} 1-0 \mathrm{~h}$ and
Fig. 2 Comparison of the toxicity scores of female and male patients. As shown, females had higher toxicity scores than males. The scores were significantly different for total toxicity $(p=0.0004)$ and haematological toxicity $(p=0.0089)$, but not for gastrointestinal toxicity $(p=0.14)$. Mean values and standard deviations (within parenthesis) are presented to the right of each plot, and confidence intervals are shown as blue- and red-shaded areas.

Each dot represents one patient

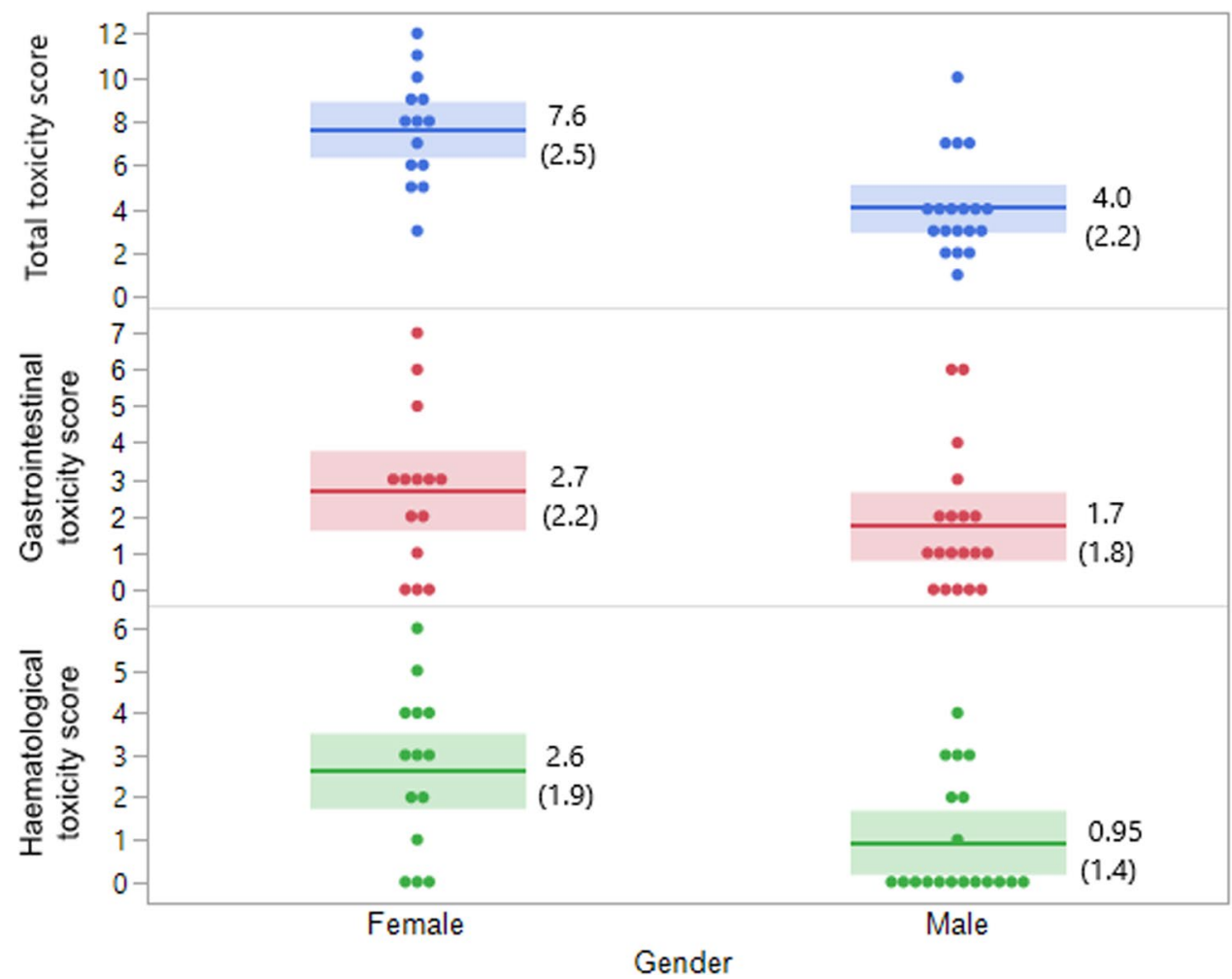


C1-24 h. This increase was not seen at $48 \mathrm{~h}$. The dUr levels were higher in females compared to males at all measurements; however, the difference was not significant. No correlation between the dUr levels and age was seen.

The dUr levels at $\mathrm{C} 1$ and $\mathrm{C} 4$ were analyzed according to given arfolitixorin dose. Since dUr values at $\mathrm{C} 4$ were only available for two of the patients receiving $240 \mathrm{mg} / \mathrm{m}^{2}$ arfolitixorin, these values were not included in the statistical analysis. The results showed that the plasma dUr levels at $\mathrm{C} 1-24 \mathrm{~h}$ increased with increasing dose of arfolitixorin (Fig. 3). As shown in the figure, one patient who received $120 \mathrm{mg} / \mathrm{m}^{2}$ arfolitixorin was an outlier, having unusually high dUr levels. When omitting this patient from the statistical analysis, the difference between the groups was still significant $(p=0.040)$. At C4-24 h, the plasma dUr level was higher in patients receiving 120 , compared to 30 and $60 \mathrm{mg} / \mathrm{m}^{2}$ arfolitixorin. However, the difference did not reach significance.

\section{Plasma dUr and toxicity}

The plasma dUr values were analyzed in patients according to need of dose reduction due to toxicity during chemotherapy (Table 1). As shown, patients who needed dose reduction had significantly higher dUr levels at $\mathrm{C} 1$ and $\mathrm{C} 4$, both at $0 \mathrm{~h}$ and $24 \mathrm{~h}$, compared to patients without need of dose reduction. Fit modelling predicting toxicity during chemotherapy was performed using effect likelihood ratio
Table 1 Association between the dUr levels ( $\mathrm{pmol} / \mathrm{ml}$ ) expressed as means \pm standard deviations at $\mathrm{C} 1$ and $\mathrm{C} 4$ and need of dose reduction (no/yes) during chemotherapy

\begin{tabular}{llll}
\hline & \multicolumn{2}{l}{ Dose reduction } & \multirow{2}{*}{$p$ value } \\
\cline { 2 - 3 } & No & Yes & \\
\hline dUr C1-0 h & $51.3 \pm 14.6$ & $71.9 \pm 37.5$ & 0.082 \\
& $n=22$ & $n=11$ & \\
dUr C1-24 h & $128.9 \pm 54.2$ & $221.9 \pm 139.7$ & 0.012 \\
& $n=19$ & $n=10$ & \\
dUr C4-0 h & $68.7 \pm 15.0$ & $100.3 \pm 47.0$ & 0.038 \\
& $n=20$ & $n=7$ & \\
dUr C4-24 h & $153.1 \pm 60.0$ & $328.2 \pm 163.5$ & 0.0030 \\
& $\mathrm{n}=18$ & $n=6$ & \\
\hline
\end{tabular}

$d U r$, deoxyuridine; $C 1$, treatment cycle $1 ; C 4$, treatment cycle 4

tests. The gender, age, and the plasma dUr C1 and dUr C4 values at $0 \mathrm{~h}$ and $24 \mathrm{~h}$ were used as explanatory variables. Before modelling, the total toxicity score (range 1-12) was divided into three groups $(\leq 3,>3$ to $\leq 8$, and $>8)$ to obtain categorical values. The results showed that gender and the dUr levels at C1-0 h and C4-24 h were predictive of total toxicity (Table 2). When the gastrointestinal toxicity score (range $0-7)$ was divided into two groups $(\leq 1$ and $>1)$ and modelled, the results showed that dUr C4-0 h was predictive for gastrointestinal toxicity. A high dUr C4-0 h was associated with a higher toxicity score. The mean haematological toxicity score (range 0-6) was divided into two
Fig. 3 Mean dUr levels at C1-24 $\mathrm{h}$ and C4-24 h by arfolitixorin dose. As shown, the dUr C1-24 h levels increased by increasing arfolitixorin dose $(p=0.023)$. At $\mathrm{C} 4-24 \mathrm{~h}$, the plasma dUr level was higher in patients receiving 120 , compared to 30 and $60 \mathrm{mg} / \mathrm{m}^{2}$ arfolitixorin but the difference did not reach significance $(p=0.31)$. Mean values and standard deviations (within parenthesis) are presented to the right of each plot, and confidence intervals are shown as blue- and red-shaded areas. Each dot represents one patient

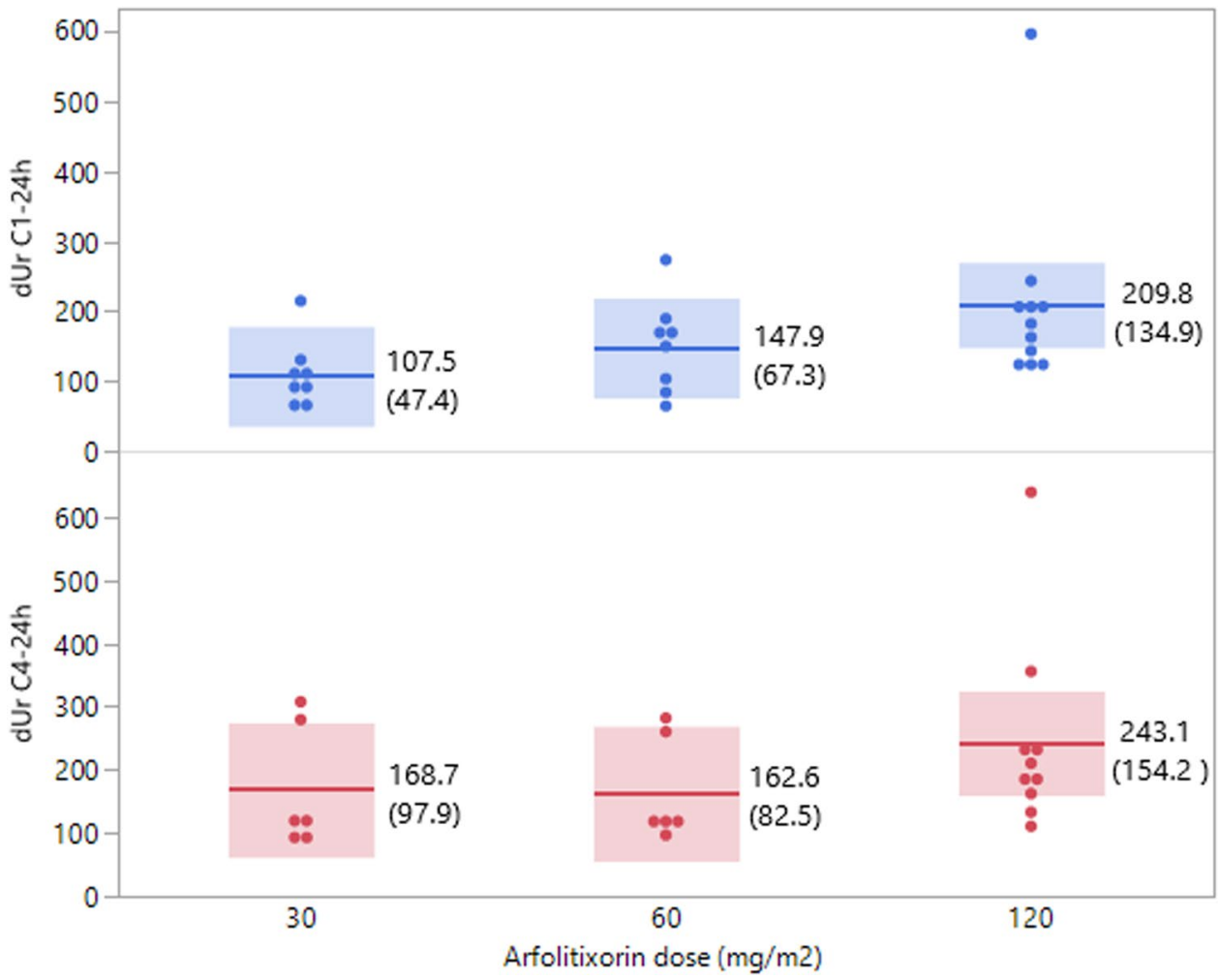


Table 2 Effect likelihood ratio tests predicting the effect of the explanatory variables on toxicity scores and clinical response

\begin{tabular}{llll}
\hline & Explanatory variable & $p$ value & $\begin{array}{l}p \text { value } \\
\text { whole } \\
\text { model }\end{array}$ \\
\hline Toxicity score & & & \\
Total & Gender & 0.0026 & 0.0011 \\
& dUr C1-0 h & 0.0046 & \\
& dUr C4-24 h & 0.0071 & \\
Gastrointestinal & dUr C4-0 h & 0.026 & 0.026 \\
Haematological & Gender & 0.0091 & 0.0071 \\
& Age & 0.021 & \\
Clinical response & Haematological toxicity score & 0.0050 & 0.018 \\
& dUr C1-24 h & 0.038 & \\
& dUr C4-24 h & 0.047 & \\
\hline
\end{tabular}

$d U r$, deoxyuridine; $C 1$, treatment cycle $1 ; C 4$, treatment cycle 4

groups $(\leq 2$, and $>2)$ and the fit model showed that gender and age were predictive of haematological toxicity. Female gender and higher age were associated with a higher haematological toxicity.

\section{Plasma dUr and clinical response}

The fit model was used to test the possibility to predict clinical response (PR/SD/PD) using gender, age, the plasma dUr $\mathrm{C} 1$ and $\mathrm{C} 4$ levels at $0 \mathrm{~h}$ and $24 \mathrm{~h}$, and the haematological toxicity score as explanatory variables. The results showed that the haematological toxicity score in combination with the dUr levels at C1-24 $\mathrm{h}$ and $\mathrm{C} 4-24 \mathrm{~h}$ correlated significantly with clinical response (Table 2). A high haematological toxicity score, a low $\mathrm{C} 1-0 \mathrm{~h}$ value, and a high C1-24 h value were associated with a better clinical response.

\section{Changes in plasma dUr in individual patients}

The plasma dUr levels at $\mathrm{C} 1-0 \mathrm{~h}, \mathrm{C} 1-24 \mathrm{~h}, \mathrm{C} 4-0 \mathrm{~h}$, and C4-24 h in individual patients $(n=21)$ were plotted into graphs to visualize alterations over time. Patients were divided into four groups based on different alteration patterns (Fig. 4). The gender, age, haematological toxicity score, clinical response, and treatment line of each patient, as well as the arfolitixorin dose and type of cytotoxic drug given, are presented in tables below the graphs. As shown, haematological toxicity was associated with clinical response in almost all of the patients; 9 out of 10 patients with haematological toxicity had PR, whereas 9 out of 11 patients without haematological toxicity had SD/PD.

\section{Discussion}

In the open-label ISO-CC-005 study, 33 patients with mCRC were treated with arfolitixorin in combination with 5-FU, alone, or in combination with a fixed dose of oxaliplatin or irinotecan \pm bevacizumab. The study was designed as a phase I/IIa dose limiting toxicity study; thus, the number of patients included in each group was limited. As the small sample size may have affected the results of the statistical analysis, the data need to be treated with caution. A strength of the study was that all patients were treated in a standardized manner by the same medical team at a single center. Another strength was that each patient represented their own control in the pharmacokinetic part of the studies, since the dUr values at baseline were compared with dUr values at different time points during treatment.

Several studies on CRC have shown that females experience a higher degree of toxicity than males [16, 22-25]. For example, a meta-analysis of the toxicity profiles of five CRC trials including more than 2,400 patients showed that females receiving 5-FU-based chemotherapy in a 5-day bolus schedule experienced more frequent and more severe toxicity than males [25]. The gender differences were consistent across treatment cycles. In another large study of CRC patients from four trials, 5-FU toxicity was found to be more extensive in females than in males in terms of maximum toxicity grade and number of different toxicity types. This gender difference persisted across a range of treatment regimens, patient characteristics, and cancer trial settings [24]. Haematological toxicity in particular, has been reported to be higher in females compared to males in some studies [24, 26]. This may be because haematological toxicity variables are measured objectively, which means that they are not subjected to any potential reporting bias. In addition to female gender, high age has been found to predict for increased grade 3/4 leucopenia in patients receiving modulated 5-FU [26].

In the present study, fewer female than male patients ( $41 \%$ vs $59 \%$ ) participated, thus, the numbers of toxicity-related events were expected to be lower compared to cohorts with an equal gender distribution. Even so, and in line with previous reports, the haematological toxicity score was significantly higher among females than males. As reviewed by Schmetzer and Flörcken [15], one of the reasons for the toxicity-related gender differences is gender-biased expression of metabolic enzymes and transporters in liver and kidney. This may lead to different pharmacokinetics, as has been described for most common anti-cancer drugs. Interestingly, both 5-FU and folates have slower clearance rates in females compared 

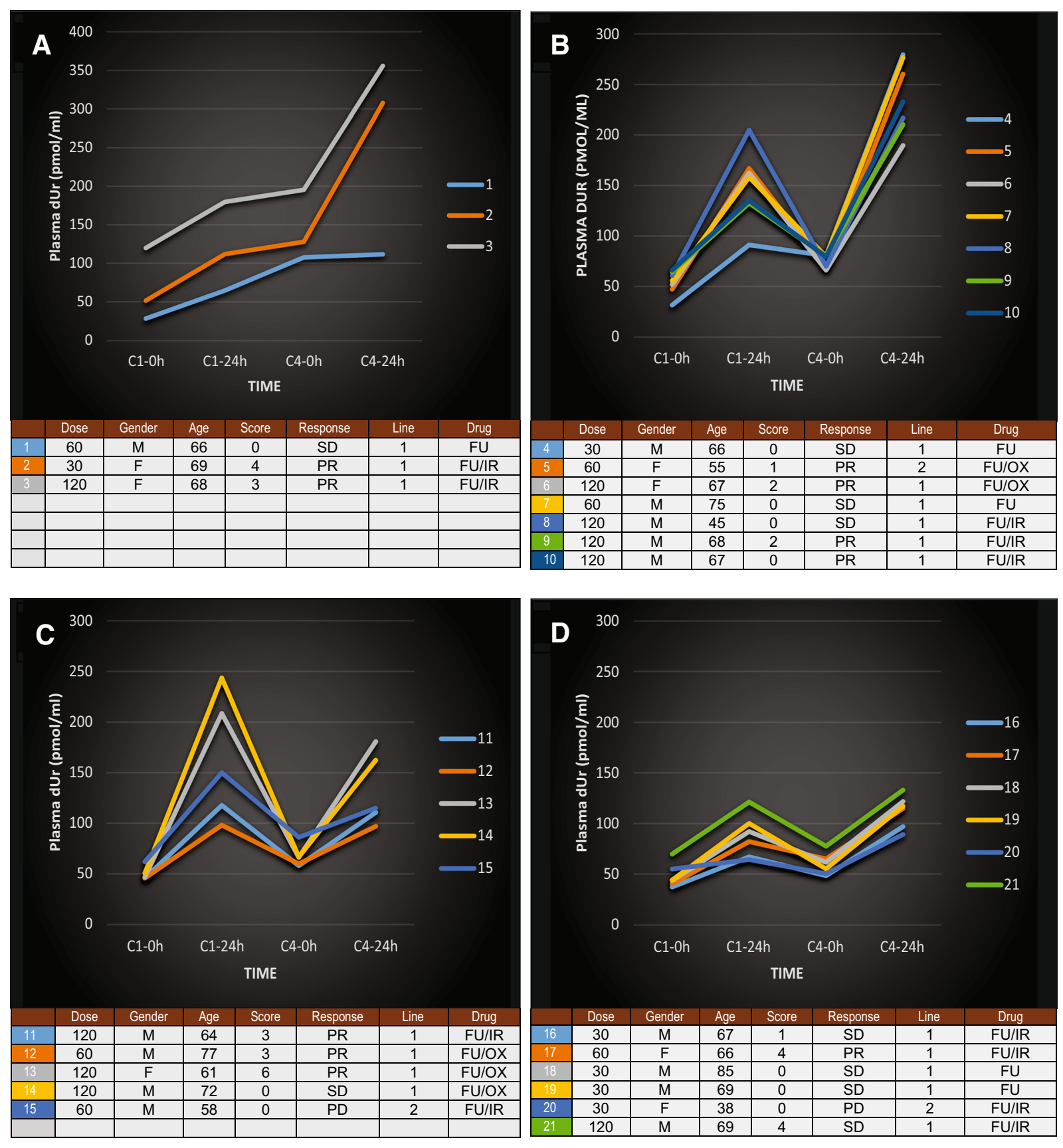

Fig. 4 Changes in plasma dUr levels over time in individual patients $(n=21)$ with mCRC, where samples were available at four time points (C1-0 h, C1-24 h, C4-0 h, C4-24 h). Patients were divided into groups based on the dUr alteration patterns. The arfolitixorin dose $(\mathrm{mg} / \mathrm{m} 2)$, gender (M or F), age (years), haematological toxicity score (0-12), clinical response (PR, SD, or PD), treatment line (1 or 2), and cytotoxic drugs [5-FU (FU), 5-FU/oxaliplatin (FU/OX), or 5-FU/ irinotecan (FU/IR)] of each patient are presented in tables below the

to males, which may explain a part of the increased toxicity $[13,14]$.

Furthermore, the results of the present study showed that the haematological toxicity score was significantly

graphs. a Three patients increased the dUr levels at each time point. b Seven patients had a higher dUr level at $\mathrm{C} 4-24 \mathrm{~h}$ compared to C1-24 h. c Five patients had a lower dUr level at C4-24 h compared to $\mathrm{C} 1-24 \mathrm{~h}$. d Six patients had a higher dUr value at C4-24 h compared to $\mathrm{C} 1-24 \mathrm{~h}$, but the dUr level was low over the entire range. It is striking that 9 out of 10 patients with haematological toxicity had PR, whereas 9 out of 11 patients without haematological toxicity had $\mathrm{SD} / \mathrm{PD}$

associated with clinical response. Since the female patients experienced greater haematological toxicity, it was not surprising that they also had a higher rate of PR compared to the male patients (50\% vs $26 \%$ ). Clear gender-dependent 
differences in response rates correlating with the risk of toxicity during chemotherapy have been reported previously. For instance, Abola et al. found that across 99 randomized oncology trials, treatments with greater all-grade toxicity compared with controls were associated with greater progression-free survival [17]. As is the case for toxicity, response rates often correlate with pharmacokinetics; however, non-pharmacokinetics may also be involved. For instance, it has been suggested that females have lower expression of dihydropyrimidine dehydrogenase (DPD), i.e., the rate-limiting catabolic enzyme for 5-FU, in their colorectal carcinomas which make them more sensitive to 5-FU [27].

As haematologic toxicity is one of the main causes of treatment discontinuation, it is important that the toxicity level reached is not too high, but high enough to achieve a good clinical response. By analyzing predictive markers like $\mathrm{dUr}$ in addition to haematological variables, it may be easier to predict the level of toxicity during treatment. When the plasma dUr levels were analyzed in the present study, a large inter-individual variation was found both before and during chemotherapy. One reason for the variation might be that the initial tissue level of dUMP differed among patients. It is known that 5-FU treatment causes increased tissue dUMP levels [28], but if a patient's initial dUMP concentration is low, the treatment may not lead to a detectable increase in plasma dUr. Similarly, treatment with folate in patients who have an initial tissue folate deficiency may not lead to TS inhibition and an increase in plasma dUr, as there will be a competition for folates between different cellular pathways [29]. Furthermore, in patients with high DPD activity, low FdUMP levels will be generated leading to less TS inhibition and lower levels of plasma dUr.

The advantage of using plasma dUr as a surrogate marker is the possibility to follow individual alterations reflecting TS inhibition over time. This has been tested previously in a few studies. For instance, elevations in dUr levels were found during treatment of patients with CRC using 5-FU or the antifolates raltitrexed and ZD9331 [6]. Significant doserelated increases in plasma dUr were also found in patients having a range of different malignancies, including CRC, and who were treated with ZD9331 [30]. In the present study, the mean dUr levels at C1-24 h increased significantly with increasing arfolitixorin dose, and at C4-24 h, the dUr level was highest in patients who received the highest dose of arfolitixorin. The increase in dUr might reflect a positive effect of arfolitixorin on TS inhibition, which should be associated with a higher risk of toxicity and possibly a better clinical response. In fact, the fit model tests showed that both the dUr C4-24 $\mathrm{h}$ and the dUr C1-0 h variables in combination with gender were associated with total toxicity. Gastrointestinal toxicity was associated with the dUr level before treatment at cycle 4 , thus, the $\mathrm{dUr} \mathrm{C} 4-0 \mathrm{~h}$ variable could be a predictive marker for gastrointestinal toxicity during 5-FU treatment. The strongest markers for haematological toxicity, however, were gender and age.

The study was performed over a limited study period; only four cycles of treatment were given, which might have had an impact on response evaluation. Even so, the evaluation after the four-cycle treatment showed very promising results with $78 \%$ of the patients having partial response or stable disease. The results further showed that haematological toxicity in combination with the dUr levels at $\mathrm{C} 1-24 \mathrm{~h}$ and C4-24 h correlated significantly with clinical response. A high dUr C4-24 h value was associated with a better clinical response, even in patients with second-line treatment. This indicates that the change in dUr levels over time may predict clinical outcome, and that it is possible to use dUr as an early prognostic marker for TS inhibition, easily obtained through a blood sample.

Although most of the patients showed an increase in plasma dUr at C4-24 h compared to C1-24 h, some actually had a lower level. This may be due to inter-individual or gender differences in the transport or metabolism of folates and 5-FU or, as mentioned, the initial concentration of dUMP and folates in tissues. Furthermore, polymorphisms in the TS gene lead to variation in its expression between individuals, which can affect plasma dUr levels as has been shown previously $[19,31,32]$. It is also possible that some patients developed resistance to 5-FU through increased TS gene expression before or during treatment [33]. In future studies, it will be of importance to study if patients who do not increase their plasma dUr levels in response to treatment will benefit from modulation of 5-FU by optimization of the arfolitixorin dose. In this regard, it will also be of value to analyze the plasma 5-FU levels during treatment to determine the 5-FU area under the curve (AUC). A positive correlation between 5-FU AUC and toxicity, as well as clinical response, has been reported recently [34]. A positive correlation between 5-FU AUC and haematological toxicity in particular has also been observed [35]. By monitoring the 5-FU AUC, it might be possible to predict the optimal 5-FU dose of each patient.

Since the ISO-CC-005 study was designed as a phase I/ IIa study with focus on safety, the inclusion criteria of the patients were broad, allowing for patients with WHO performance status 0-2, and a life expectancy of at least three months to be included. Thus, some of the patients were frail, which might have influenced the severity of toxicity as well as the clinical response. Also of importance is the fact that a few patients received 5-FU as bolus injection, whereas other received the drug as a combination of bolus injection and continuous infusion. The different scheduling of 5-FU might have affected the specificity for TS and duration of TS inhibition, which in turn could have influenced toxicity and response. However, as mentioned, gender-related differences 
regarding 5-FU-related toxicity seem to be persistent across treatment regimens and different cancer trial settings [24], which strengthen the results.

\section{Conclusion}

Finding markers that reflect TS inhibition during 5-FUbased treatment is essential to identify patients who are at risk of developing severe toxicity and who responds to treatment. Previous studies have suggested that dUr might be a useful surrogate marker of TS inhibition. The present study showed the plasma dUr concentration before and during administration of 5-FU-based chemotherapy modulated by arfolitixorin was significantly associated with both toxicity and early clinical response. Based on these data, we conclude that dUr is a potential surrogate marker for TS inhibition, and that modulation of TS activity might be possible by individualizing the dosage of arfolitixorin. Analysis of plasma dUr as well as other putatively informative 5-FUrelated markers will be valuable to improve individualization of chemotherapy. Studies of additional, more homogenous cohorts of patients with CRC are presently ongoing, where separate prediction models will be evaluated for female and male patients. These models will hopefully be useful for development of gender-adapted and individual therapies.

\section{Availability of data and material}

The datasets used and/or analyzed during the current study are available from the corresponding author on reasonable request.

\footnotetext{
Acknowledgements We would like to thank the patients who participated in this trial as well as the investigators and site staff. We thank research nurses H. Björkqvist and A.-L. Helminen for help with implementation of the study, research nurse L. Munro for clinical database assistance, J. Flach and M. Åkerström for technical assistance, and L. Skintemo, Isofol Global Clinical Trial Manager, for the 005-Study coordination. M. Aström is acknowledged for help with the statistical analyses.
}

Funding Open access funding provided by University of Gothenburg. Isofol Medical $\mathrm{AB}$ designed and funded the safety and tolerability study (ISO-CC-005). The pharmacokinetics analysis of dUr was performed as an academic study at the Sahlgrenska Academy at University of Gothenburg, Sweden, supported by Grants from the Swedish Cancer Society [CAN 2015/499], the King Gustav V Jubilee Clinic Foundation for Cancer Research [2016:70], the Swedish state under the LUA/ ALF agreement [ALFGBG-426941], the IngaBritt and Arne Lundberg Foundation [335/07].

\section{Compliance with ethical standards}

Conflicts of interest RT is an employee of Isofol. BG and EO are stockholders of Isofol. BG and HT are immediate family members. Other authors declare no competing interests.

Ethics approval The study was done in accordance with the Declaration of Helsinki and adhered to the ICH Good Clinical Practice Guidelines. The protocol complied with local regulations and was approved by the Institutional Review Board, the Swedish National Competent Authority, Medical Products Agency (MPA), and the Regional Ethics Committee of Gothenburg (395-16/501-14 and 2019-06166).

Consent to participate All included patients provided written informed consent to participate.

Open Access This article is licensed under a Creative Commons Attribution 4.0 International License, which permits use, sharing, adaptation, distribution and reproduction in any medium or format, as long as you give appropriate credit to the original author(s) and the source, provide a link to the Creative Commons licence, and indicate if changes were made. The images or other third party material in this article are included in the article's Creative Commons licence, unless indicated otherwise in a credit line to the material. If material is not included in the article's Creative Commons licence and your intended use is not permitted by statutory regulation or exceeds the permitted use, you will need to obtain permission directly from the copyright holder. To view a copy of this licence, visit http://creativecommons.org/licenses/by/4.0/.

\section{References}

1. Bray F, Ferlay J, Soerjomataram I, Siegel RL, Torre LA, Jemal A (2018) Global cancer statistics 2018: GLOBOCAN estimates of incidence and mortality worldwide for 36 cancers in 185 countries. CA Cancer J Clin 68(6):394-424. https://doi.org/10.3322/ caac. 21492.

2. van de Velde CJ, Boelens PG, Borras JM, Coebergh JW, Cervantes A, Blomqvist L, Beets-Tan RG, van den Broek CB, Brown G, Van Cutsem E, Espin E, Haustermans K, Glimelius B, Iversen LH, van Krieken JH, Marijnen CA, Henning G, Gore-Booth J, Meldolesi E, Mroczkowski P, Nagtegaal I, Naredi P, Ortiz H, Pahlman L, Quirke P, Rodel C, Roth A, Rutten H, Schmoll HJ, Smith JJ, Tanis PJ, Taylor C, Wibe A, Wiggers T, Gambacorta MA, Aristei C, Valentini V (2014) EURECCA colorectal: multidisciplinary management: European consensus conference colon and rectum. Eur J Cancer 50 (1):1 e1-1 e34. https://doi.org/10.1016/j. ejca.2013.06.048.

3. Van Cutsem E, Cervantes A, Adam R, Sobrero A, Van Krieken JH, Aderka D, Aranda Aguilar E, Bardelli A, Benson A, Bodoky G, Ciardiello F, D'Hoore A, Diaz-Rubio E, Douillard JY, Ducreux M, Falcone A, Grothey A, Gruenberger T, Haustermans K, Heinemann V, Hoff P, Kohne CH, Labianca R, Laurent-Puig P, Ma B, Maughan T, Muro K, Normanno N, Osterlund P, Oyen WJ, Papamichael D, Pentheroudakis G, Pfeiffer P, Price TJ, Punt C, Ricke J, Roth A, Salazar R, Scheithauer W, Schmoll HJ, Tabernero J, Taieb J, Tejpar S, Wasan H, Yoshino T, Zaanan A, Arnold D (2016) ESMO consensus guidelines for the management of patients with metastatic colorectal cancer. Ann Oncol 27(8):1386-1422. https://doi.org/10.1093/annonc/mdw235.

4. Schmoll HJ, Van Cutsem E, Stein A, Valentini V, Glimelius B, Haustermans K, Nordlinger B, van de Velde CJ, Balmana J, Regula J, Nagtegaal ID, Beets-Tan RG, Arnold D, Ciardiello F, Hoff P, Kerr D, Kohne CH, Labianca R, Price T, Scheithauer 
W, Sobrero A, Tabernero J, Aderka D, Barroso S, Bodoky G, Douillard JY, El Ghazaly H, Gallardo J, Garin A, Glynne-Jones R, Jordan K, Meshcheryakov A, Papamichail D, Pfeiffer P, Souglakos I, Turhal S, Cervantes A (2012) ESMO Consensus Guidelines for management of patients with colon and rectal cancer. a personalized approach to clinical decision making. Ann Oncol 23 (10):2479-2516. https://doi.org/10.1093/annonc/mds236.

5. Gustavsson B, Carlsson G, Machover D, Petrelli N, Roth A, Schmoll HJ, Tveit KM, Gibson F (2015) A review of the evolution of systemic chemotherapy in the management of colorectal cancer. Clin Colorectal Cancer 14(1):1-10. https://doi.org/10.1016/j. clcc.2014.11.002.

6. Ford HE, Mitchell F, Cunningham D, Farrugia DC, Hill ME, Rees C, Calvert AH, Judson IR, Jackman AL (2002) Patterns of elevation of plasma 2'-deoxyuridine, a surrogate marker of thymidylate synthase (TS) inhibition, after administration of two different schedules of 5-fluorouracil and the specific TS inhibitors raltitrexed (Tomudex) and ZD9331. Clin Cancer Res 8(1):103-109.

7. Spears CP, Gustavsson BG, Mitchell MS, Spicer D, Berne M, Bernstein L, Danenberg PV (1984) Thymidylate synthetase inhibition in malignant tumors and normal liver of patients given intravenous 5-fluorouracil. Cancer Res 44(9):4144-4150.

8. Thirion P, Michiels S, Pignon JP, Buyse M, Braud AC, Carlson RW, O'Connell M, Sargent P, Piedbois P, Meta-Analysis Group in C (2004) Modulation of fluorouracil by leucovorin in patients with advanced colorectal cancer: an updated metaanalysis. J Clin Oncol 22(18):3766-3775. https://doi.org/10.1200/ JCO.2004.03.104.

9. Taflin H, Wettergren Y, Odin E, Derwinger K (2014) Folate levels measured by LC-MS/MS in patients with colorectal cancer treated with different leucovorin dosages. Cancer Chemother Pharmacol 74(6):1167-1174. https://doi.org/10.1007/s00280-014-2591-9.

10. Odin E, Sonden A, Carlsson G, Gustavsson B, Wettergren Y (2019) Folate pathway genes linked to mitochondrial biogenesis and respiration are associated with outcome of patients with stage III colorectal cancer. Tumour Biol 41(6):1010428319846231. https://doi.org/10.1177/1010428319846231.

11. Odin E, Sonden A, Gustavsson B, Carlsson G, Wettergren Y (2015) Expression of folate pathway genes in stage III colorectal cancer correlates with recurrence status following adjuvant bolus 5-FU-based chemotherapy. Mol Med 21:597-604. https://doi. org/10.2119/molmed.2014.00192.

12. Taflin H, Odin E, Derwinger K, Carlsson G, Gustavsson B, Wettergren Y (2018) Relationship between folate concentration and expression of folate-associated genes in tissue and plasma after intraoperative administration of leucovorin in patients with colorectal cancer. Cancer Chemother Pharmacol 82(6):987-997. https ://doi.org/10.1007/s00280-018-3690-9.

13. Mader RM, Steger GG, Rizovski B, Djavanmard MP, Scheithauer W, Jakesz R, Rainer H (1995) Stereospecific pharmacokinetics of rac-5-methyltetrahydrofolic acid in patients with advanced colorectal cancer. Br J Clin Pharmacol 40(3):209-215.

14. Milano G, Etienne MC, Cassuto-Viguier E, Thyss A, Santini J, Frenay M, Renee N, Schneider M, Demard F (1992) Influence of sex and age on fluorouracil clearance. J Clin Oncol 10(7):11711175. https://doi.org/10.1200/JCO.1992.10.7.1171.

15. Schmetzer O, Flörcken A (2012) Sex Differences in the drug therapy for oncologic diseases. In: Regitz-Zagrosek V (eds) Sex and gender differences in pharmacology handbook of experimental pharmacology. Springer, Berlin, Heidelberg, pp 411-442. https ://doi.org/10.1007/978-3-642-30726-3_19.

16. Stein BN, Petrelli NJ, Douglass HO, Driscoll DL, Arcangeli G, Meropol NJ (1995) Age and sex are independent predictors of 5-fluorouracil toxicity. Analysis of a large scale phase III trial. Cancer 75 (1):11-17. https://doi.org/10.1002/1097-0142(19950 101) $75: 1<11$ ::aid-cncr2820750104>3.0.co;2-n.
17. Abola MV, Prasad V, Jena AB (2014) Association between treatment toxicity and outcomes in oncology clinical trials. Ann Oncol 25(11):2284-2289. https://doi.org/10.1093/annonc/mdu444.

18. Wettergren Y, Taflin H, Odin E, Kodeda K, Derwinger K (2015) A pharmacokinetic and pharmacodynamic investigation of Modufolin(R) compared to Isovorin(R) after single dose intravenous administration to patients with colon cancer: a randomized study. Cancer Chemother Pharmacol 75(1):37-47. https://doi. org/10.1007/s00280-014-2611-9.

19. Danenberg PV, Gustavsson B, Johnston P, Lindberg P, Moser R, Odin E, Peters GJ, Petrelli N (2016) Folates as adjuvants to anticancer agents: Chemical rationale and mechanism of action. Crit Rev Oncol Hematol 106:118-131. https://doi.org/10.1016/j.critr evonc.2016.08.001.

20. Hoff PM, Saad ED, Costa F, Coutinho AK, Caponero R, Prolla G, Gansl RC (2012) Literature review and practical aspects on the management of oxaliplatin-associated toxicity. Clin Colorectal Cancer 11(2):93-100. https://doi.org/10.1016/j.clcc.2011.10.004.

21. Lucas AS, O’Neil BH, Goldberg RM (2011) A decade of advances in cytotoxic chemotherapy for metastatic colorectal cancer. Clin Colorectal Cancer 10(4):238-244. https://doi.org/10.1016/j. clcc.2011.06.012.

22. Carlsson G, Odin E, Gustavsson B, Wettergren Y (2014) Pretherapeutic uracil and dihydrouracil levels in saliva of colorectal cancer patients are associated with toxicity during adjuvant 5-fluorouracil-based chemotherapy. Cancer Chemother Pharmacol 74(4):757-763. https://doi.org/10.1007/s00280-014-2553-2.

23. Wettergren Y, Carlsson G, Odin E, Gustavsson B (2012) Pretherapeutic uracil and dihydrouracil levels of colorectal cancer patients are associated with sex and toxic side effects during adjuvant 5-fluorouracil-based chemotherapy. Cancer 118(11):2935-2943. https://doi.org/10.1002/cncr.26595.

24. Chansky K, Benedetti J, Macdonald JS (2005) Differences in toxicity between men and women treated with 5 -fluorouracil therapy for colorectal carcinoma. Cancer 103(6):1165-1171. https://doi. org/10.1002/cncr.20878.

25. Sloan JA, Goldberg RM, Sargent DJ, Vargas-Chanes D, Nair S, Cha SS, Novotny PJ, Poon MA, O'Connell MJ, Loprinzi CL (2002) Women experience greater toxicity with fluorouracil-based chemotherapy for colorectal cancer. J Clin Oncol 20(6):14911498. https://doi.org/10.1200/JCO.2002.20.6.1491.

26. Zalcberg J, Kerr D, Seymour L, Palmer M (1998) Haematological and non-haematological toxicity after 5-fluorouracil and leucovorin in patients with advanced colorectal cancer is significantly associated with gender, increasing age and cycle number. Tomudex International Study Group. Eur J Cancer 34 (12):1871-1875. https://doi.org/10.1016/s0959-8049(98)00259-7.

27. Yamashita K, Mikami Y, Ikeda M, Yamamura M, Kubozoe T, Urakami A, Yoshida K, Kimoto M, Tsunoda T (2002) Gender differences in the dihydropyrimidine dehydrogenase expression of colorectal cancers. Cancer Lett 188(1-2):231-236. https://doi. org/10.1016/s0304-3835(02)00435-4.

28. Peters GJ, Backus HH, Freemantle S, van Triest B, CodacciPisanelli G, van der Wilt CL, Smid K, Lunec J, Calvert AH, Marsh S, McLeod HL, Bloemena E, Meijer S, Jansen G, van Groeningen CJ, Pinedo HM (2002) Induction of thymidylate synthase as a 5-fluorouracil resistance mechanism. Biochim Biophys Acta 1587(2-3):194-205. https://doi.org/10.1016/s0925 $-4439(02) 00082-0$.

29. Peters GJ, van der Wilt CL, van Triest B, Codacci-Pisanelli G, Johnston PG, van Groeningen CJ, Pinedo HM (1995) Thymidylate synthase and drug resistance. Eur J Cancer 31A(7-8):1299-1305. https://doi.org/10.1016/0959-8049(95)00172-f.

30. Plummer R, Rees C, Hughes A, Beale P, Highley M, Trigo J, Gokul S, Judson I, Calvert H, Jackman A, Mitchell F, Smith R, Douglass E (2003) A phase I trial of ZD9331, a water-soluble, 
nonpolyglutamatable, thymidylate synthase inhibitor. Clin Cancer Res 9(4):1313-1322.

31. Li KM, Rivory LP, Hoskins J, Sharma R, Clarke SJ (2007) Altered deoxyuridine and thymidine in plasma following capecitabine treatment in colorectal cancer patients. Br J Clin Pharmacol 63(1):67-74. https://doi.org/10.1111/j.1365-2125.2006.02710.x.

32. de Bock CE, Garg MB, Scott N, Sakoff JA, Scorgie FE, Ackland SP, Lincz LF (2011) Association of thymidylate synthase enhancer region polymorphisms with thymidylate synthase activity in vivo. Pharmacogenomics J 11(4):307-314. https://doi. org/10.1038/tpj.2010.43.

33. Watson RG, Muhale F, Thorne LB, Yu J, O'Neil BH, Hoskins JM, Meyers MO, Deal AM, Ibrahim JG, Hudson ML, Walko CM, McLeod HL, Auman JT (2010) Amplification of thymidylate synthetase in metastatic colorectal cancer patients pretreated with 5-fluorouracil-based chemotherapy. Eur J Cancer 46(18):33583364. https://doi.org/10.1016/j.ejca.2010.07.011.
34. Fang L, Jiang Y, Yang Y, Zheng Y, Zheng J, Jiang H, Zhang S, Lin L, Zheng J, Zhang S, Zhuang X (2016) Determining the optimal 5-FU therapeutic dosage in the treatment of colorectal cancer patients. Oncotarget 7(49):81880-81887. https://doi.org/10.18632 /oncotarget.11980.

35. Garg MB, Lincz LF, Adler K, Scorgie FE, Ackland SP, Sakoff JA (2012) Predicting 5-fluorouracil toxicity in colorectal cancer patients from peripheral blood cell telomere length: a multivariate analysis. Br J Cancer 107(9):1525-1533. https://doi.org/10.1038/ bjc.2012.421.

Publisher's Note Springer Nature remains neutral with regard to jurisdictional claims in published maps and institutional affiliations. 